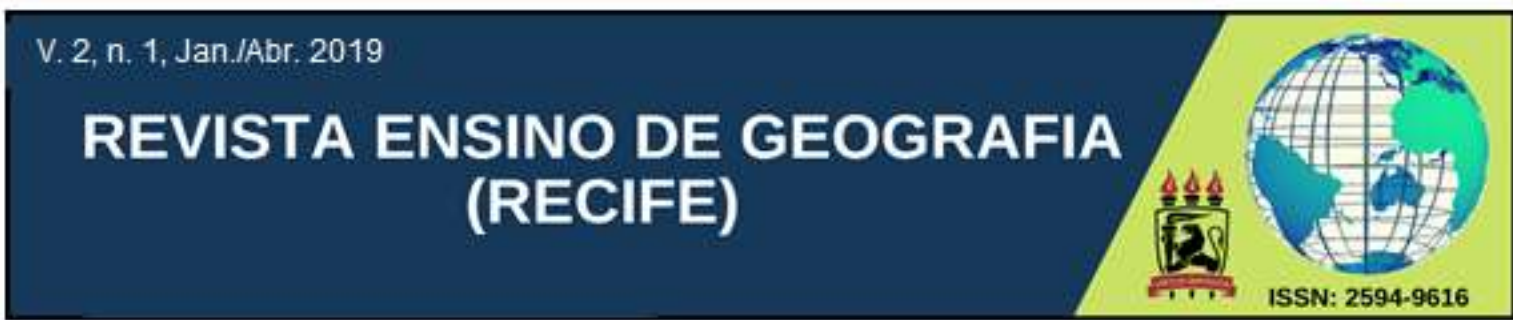

\title{
DO TRADICIONALISMO À POSSIBILIDADE DE SUBVERSÃO: DIÁLOGOS (IM) POSSÍVEIS ENTRE GEOGRAFIA E GÊNERO
}

\author{
Tâmara Carla Gonçalves Bezerra \\ Graduanda do curso de Licenciatura em Geografia/UFPE \\ tamara.g.bezerra@gmail.com \\ ORCID iD: https://orcid.org/0000-0001-8746-1499
}

Artigo recebido em 06/05/2019 e aceito em 13/05/2019

\begin{abstract}
RESUMO: Definir o espaço-escola é difícil. Todas as suas espacialidades atribuem-lhe um caráter contraditório, tanto quanto os atributos que caracterizam o espaço geográfico. Neste trabalho, acatando às múltiplas facetas que a escola apresenta, concebemo-la enquanto um reflexo ativo (produto e produtor) da sociedade. Indissociável a esta realidade, o ensino de geografia se (re)configura no espaço-tempo de acordo com os ordenamentos sociais vigentes. Na contemporaneidade, se vê marcado pela emergência de debater temáticas arredadas por um passado não tão distante. Por isto, este trabalho toma como objetivo refletir aceca dos estorvos a que a educação geográfica construíra espacialmente ao longo dos anos, buscando ampliar seu campo de estudo. A fim de compreender as (im)possibilidades de dialogar com temáticas tão polêmicas quanto emergentes, se faz o recorte das questões de gênero com o ensino de geografia. A problemática se configura à medida em que desvelamos que o ensino atual está arraigado às amarras de seu tradicionalismo. Espera-se, aqui, contribuir com a (auto)crítica necessária à dimensão concreta da educação geográfica, a fim de (des)construir e analisar a viabilidade de novos itinerários.
\end{abstract}

Palavras-chave: Ensino; Gênero; Educação Geográfica.

\section{FROM TRADICIONALISM TO SUBVERSIVE POSSIBILITIE: (IM)POSSIBLE DIALOGS BETWEEN GEOGRAPHY AND GENRE}

\begin{abstract}
Defining school space is difficult. All its spatialities attribute to it a contradictory character, as much as the attributes that characterize the geographic space. In this work, according to the multiple facets that the school presents, we conceive it as an active reflection (product and producer) of society. Indissociable to this reality, the teaching of geography is (re)configured in space-time according to the current social order. In contemporaneity, it is marked by the emergence of debating themes that are surrounded by a not so distant past. Therefore, this work aims to reflect the disappearance of the obstacles that geographic education spatially built over the years, seeking to expand its field of study. In order to understand the (im)possibilities of dialoguing with controversial issues as they are emerging, the question of gender with the teaching of geography as cutout. The problematic is configured as we reveal that the current teaching is rooted in the bonds of its traditionalism. It is hoped, here, to contribute the (self) criticism necessary to the concrete dimension of geographic education, in order to (de) construct and analyze the feasibility of new itineraries.
\end{abstract}

Keywords: Teaching; Genre; Geographical education. 


\section{INTRODUÇÃO}

O surgimento da escola advém de um contexto histórico-geográfico capitalístico em que a burguesia, lê-se classe dominante, estimulou ao proletariado um ensino voltado à praticidade do mundo fabril, recém industrial. Até hoje, fortes marcas deste contexto nos amedrontam a pensar o ensino crítico, e mais precisamente, o ensino crítico de geografia, concebida como uma matéria escolar maçante e descritiva. Pensar criticamente a educação geográfica é lidar com as múltiplas facetas espaço-temporais da sociedade, uma vez que "No seu movimento permanente, em sua busca incessante de geografização, a sociedade está subordinada à lei do espaço preexistente" (SANTOS, 1988, p. 26), e por mais que soe pleonástico, nos cabe ponderar que a escola é um reflexo ativo da sociedade.

Aqui, pensaremos na relação contraditória e indissociável do espaço geográfico (SANTOS, 1994) com o ensino de geografia na contemporaneidade, trazendo à tona as questões de gênero emergentes e necessárias ao debate, para refletir sobre os possíveis diálogos entre a educação geográfica e as questões de gênero da contemporaneidade.

Pautada como temática transversal pelos documentos oficiais que, em um plano hipotético, regem a educação brasileira, - sendo estes as Diretrizes Curriculares Nacionais (DCNs), os Parâmetros Curriculares Nacionais (PCNs) e a Base Nacional Comum Curricular (BNCC), "gênero" se constitui também como categoria de análise funcional que subsidia(ria) a geografia escolar a fim do saber ouvir os gritos silenciosos dos grupos sociais minoritários.

Justamente pela possibilidade de flexão na conjugação temporal (e espacial) do verbo subsidiar, objetiva-se aqui refletir como a geografia escolar sofreu influências das organizações socioespaciais, bem como pode lidar com as amarras que a agrilhoam à continência retroativa ao tradicionalismo; há-se, necessariamente, de discorrer acerca da rede de relações que imbricam esta presumível dominação.

Para isso, se faz imprescindível compreender que a demanda social, lida como "necessidade" de escrever, ler e contar, evidencia-nos certas problemáticas do espaço-escola, onde se atribuiu funcionalidades de um imaginário coletivo técnico à práxis pedagógica, mecanizando o ensino da geografia e (re)produzindo sociabilidades e socializações de uma sociedade hierarquizada, desigual e excludente. Enquanto uma sistematização de saberes, a geografia escolar não escapa à (in)sensibilidade do mundo em que está inserida, bem como diz Moreira (1982), “a geografia serve para desvendar máscaras sociais”. 


\section{TECENDO E DESTECENDO: A EDUCAÇÃO GEOGRÁFICA NO ESPAÇO- TEMPO}

Em um de seus contos de fada contemporâneos, intitulado A Moça Tecelã (1982), Marina Colasanti retrata a vida de uma jovem moça através de seu tear. É costurando e descosturando que a vida da personagem se faz simples e poética. Às cores, seus humores; ao futuro, a imaginação. Com o passar dos tempos, "Tecer era tudo o que fazia... tecendo e tecendo, ela própria trouxe o tempo em que se sentiu sozinha" (COLASANTI, 1982, p. 20). Eis que tece um marido que diferentemente do que esperava, frustra suas expectativas de companheirismo. Mas seu poder de tear, apesar de explorado por ele, ainda era seu, e só ela, com altiveza e coragem, teve a capacidade de reconhecer o seu estado para então, destecê-lo.

Por décadas, o ensino de geografia nas escolas se viu na mesma situação em que a moça tecelã: cerceada(o), limitada(o) por indivíduos cujos interesses mantinham uma ordem espacial historicamente construída. Segundo Bourdieu (2001, p. 11), “As diferentes classes e fracções de classes estão envolvidas numa luta propriamente simbólica para imporem a definição do mundo social mais conforme aos seus interesses". Considera-lo é entender que durante os séculos XIX até meados do século XX, a geografia incorporou-se às escolas tendo como princípio a fundamental formar cidadãos patrióticos.

Decerto, as formas de organização espacial perpassam os muros da escola e moldam a liberdade didática do professorado. Durante a época referida, a geografia escolar apresentara um caráter informativo e transmissor, o que nos remete novamente a Bourdieu, conjunto a Passeron (2009). Ambos os autores tecem as marcas e matrizes que sublimam as ramificações outrora recônditas por detrás do sistema de ensino - o que definitivamente não foge à escola e à geografia escolar.

Por intermédio da violência simbólica, dissimulada e arbitrariamente, a ação pedagógica subjuga os indivíduos a fim de normatiza-los de acordo com uma "ideologia dominante", isso acontece mediante eufemismos; a figuração do(a) professor(a) como detentor do conhecimento e a escola como lócus de verdades concretas, a hierarquização da estrutura organizacional, dentre outros aspectos circunscritos. Entende-se por ideologia dominante não o que se quantifica numericamente, mas o que qualificadamente molda determinados espaços e mantém privilégios de gênero, classe e etnia, principalmente através do fomento de um discurso romantizado da escola, em que a "autoridade" do(a) professor(a) é vista como prerrogativa ao ensino de qualidade - lê-se disciplinar. 
O tradicionalismo da geografia escolar, estruturado sob a égide da epistemologia da ciência geográfica, perpassa questões curriculares que tangem à educação básica e a própria formação de professores, eis o porquê se mantém consolidado até hoje nas práticas pedagógicas: fora estruturado, é resultado da dialogicidade e incongruência da dinâmica socioespacial, e por sê-lo, se contextualiza de acordo com o funcionamento da sociedade.

O saber geográfico desdobra-se ao que Marina Colasanti constrói e transmite em A Moça Tecelã. Sob o óbice da própria práxis, a Geografia se renova em sua corrente Crítica e possibilita análises mais aprofundadas sobre a cotidianidade do espaço. Desigualdades agora são questionadas, e a descrição se torna um adendo aos trabalhos científicos. Tecendo e destecendo, informações tornam-se conhecimento, e a ciência, apesar de tentativas desqualificadas de censura, progride. Mas o tear da escola, numa poética para além dos escritos de Colasanti, nos faz questionar o seu próprio tecer. Como coloca Aristóteles, a arte imita a vida.

É inegável os avanços tidos com a renovação da geografia, o incremento de possibilidades de interpretação nas diferentes temáticas evidencia o grande ponto da contemporaneidade. No que convém à geografia escolar, segundo Copatti (2017), o aporte analítico da Geografia Crítica desencadeou reflexões a respeito do saber geográfico construído nas escolas, buscando desenvolver com o alunado, uma relação dialógica em que ambos se fazem, via autonomia, sujeitos da ação.

Entrementes, interlocução do ensino de geografia com questões emergentes não se faz com afinco pois certamente a educação geográfica, tampouco sua ciência, romperam com as idealizações que há tempos e espaços, foram edificadas. Na contraditoriedade do espaço geográfico, a escola e suas rede de relações (imbricadas no ensino) são reflexos de um tecido social reprodutor de desigualdades sociais, levando-nos a crer na importância de desvelar a perversidade de um sistema socioeducativo que ainda enxerga estudantes enquanto produtos de relações sociais hierarquizadas socialmente, isto em termos de classe, etnia, gênero e sexualidade.

É a serviço da hegemonia heterossexual que a escola enquanto espaço e a prática enquanto ação abrem margem para o desencadeamento da heteronormatividade compulsória, mediante determinações históricas de papéis sociais aos diferentes gêneros, tratam como habitual a normatização dos corpos e a definição comportamental dos próprios estudantes e de como se sucede as avaliações disciplinares a estes. Todo estereótipo de sexualidade “desejável" e esperado a(o) outra(o) se faz pauta importante às discussões interseccionais de 
gênero; primeiro porque evidencia que os corpos não são entes vazios - pulsam desejo e seus comportamentos falam sobre quem representam. Segundo porque, passando despercebida, a imposição da heteronormatividade se vê imbuída de preconceitos de gênero, reforçando condutas sociais que avigoram a construção de identidades binárias, subvertendo a criticidade e a autonomia esperada para um ensino condizente com o mundo contemporâneo.

Esta compulsão heteronormativa, vista enquanto dispositivo de sexualidade que "institui e destitui identidades, dita comportamentos, práticas, representações e, sobretudo, auto representações" (SWAIN, 2009, p. 1), vai de acordo às concepções moralistas fundamentadas sob a óptica de um imaginário coletivo, que ainda toma como preceito básico à sua organização, significações religiosas traduzidas ante a configuração da moral e dos bons costumes, concebido como dogmas. Neste prumo, a inserção dos debates de gênero no ensino de geografia - e das demais ciências, vê-se debilitado por 4 considerações:

1. A ciência é demasiadamente conservadora;

2. Em relação ao ensino, julga-se desnecessário à educação geográfica debater questões de gênero;

3. Se o faz, têm caráter doutrinador;

4. Gênero e sexualidade são temáticas de responsabilidade familiar.

Concebendo o discurso enquanto um conjunto sistemático de significados, criados diante um contexto sociopolítico em que se relacionam intimamente às estruturas sociais (FOUCAULT, 1996), tais considerações fomentam uma produção discursiva machista e excludente, divergindo da romantização a que fora atribuída o papel escola, tecida enquanto instituição do diálogo, da construção... Isto, nem sempre. Como considera Miskolci (2005),

\footnotetext{
A instituição escolar tende a invisibilizar a sexualidade em um jogo de pressupostos, inferências não apresentadas e silêncios. Pressupõe-se, por exemplo, que a sexualidade é assunto privado ou, ao menos, restrito ao lado dos sujeitos o tempo todo e não tem como ser alocada no espaço ou em algum período de tempo. Ninguém se despe da sexualidade ou a deixa em casa como um acessório do qual pode-se despojar. Na escola, também se infere que todos se interessam ou se interessarão por pessoas do sexo oposto e que suas práticas sexuais seguirão um padrão reprodutivo. (MISKOLCI, 2005, p. 17-18).
}

Ao reforçar a ideia moralista e romantizada de que a escola "não é ambiente para se discutir isso" (ditos comuns a se ler e ouvir nas diversas mídias sociais, acerca dos debates de gênero no âmbito da educação), faz-se da instituição, "cúmplice" dos condicionamentos heteronormativos (FACCO, 2011); numa cadeia reprodutiva, os corpos escolarizados, acabam 
por serem, de fato, agentes ativos na reprodução da ordem social, arraigando o sistema de ensino à dominação (BOURDIEU; PASSERON, 2009).

Concebendo o espaço escolar como lócus para formação do sujeito cidadão, é inegável o contato tido com padrões comportamentais, construídos e regidos por valores e normas de uma falsa gestão democrática, em que a laicidade não cabe às estreitas condutas moralistas, enfatizando os vários níveis escalares e hierárquicos do sistema de ensino, a escola torna-se "veículo, muitas vezes, de ideologias e de uma visão de mundo que cristaliza práticas discriminatórias sejam estas de raça/etnia, de orientação sexual e/ou de gênero." (ALCÁNTARA COSTA, TEIXEIRA, MACEDO, 2011, p. 8).

Vide toda conjuntura explicitada, o ensino de geografia sobrevive às transformações no espaço e no tempo e se molda conforme os ordenamentos sociais. Por tanta inconstância, a plasticidade em que a educação geográfica se encontra acaba por fragilizar o próprio objeto de estudo da ciência geográfica: o espaço; distanciando estudantes da própria realidade e condição em que vive, isso descava-se ainda mais quando desigualdades são, como exposto, mediatizadas pelo funcionamento escolar.

Rivera (2012, apud. BOTÊLHO, 2018) defende que a educação geográfica em suas ramificações teórico-práticas (vide a formação de professores e as práticas pedagógicas) deve associar-se ao espaço vivido em sua cotidianidade. À continência retroativa da dominação de classe, gênero e etnia, pondero ainda que herdamos epistemologicamente, uma ciência à serviço de um objetivismo que neutralizara durante muito tempo os estudos geográficos. Advindo dessa articulação, o ensino seguira no mesmo prumo, contando ainda com amarras enraizadas no passado de uma sociedade colonizada e que até hoje, é refém do patriarcalismo em seu semblante mais eufemístico.

É preciso desmistificar o outro como ameaça e a diversidade como perigo. A serventia do ensinar com a Geografia, de acordo com Couto (2010), ruma em direção a estas leituras cidadãs que provocam os estereótipos aceitos como corretos e problematizam os preconceitos diários que todos estamos sujeitos a cometer. $\mathrm{O}$ individualismo, elemento crucial da lógica aplicacionista que fomenta a competitividade entre os diferentes, não permite construir sentido sobre e para uma coletividade. Como, pois, pensar em cidadania diante disto? É neste momento que nos deparamos com a provisoriedade e a ilusão que alimenta o sentido e o significado (no singular, pois não admite outra forma) da formação cidadã pregada pelos instrumentos político-educacionais validados pelo Estado. O outro, o nós, precisa ser espaço de diálogo para a subversão de uma Geografia aplicada ao rigor metódico conteudista, tornando-se uma Geografia da vida, da subjetividade e das rupturas com a ausência da diversidade. (BOTÊLHO, 2018, p. 65) 
Coube-nos neste segmento, evidenciar as amarras que agrilhoam o ensino de geografia. Sejam essas pretéritas, atuais e futuras, dialeticamente, se fizeram, e continuam por se fazerem, respaldadas sob a dinamicidade do espaço.

\section{GÊNERO E EDUCAÇÃo GEOGRÁFICA: UM DIÁLOGO NECESSÁRIO}

Quando nos atemos às questões de gênero, comumente direcionamos nossos olhares sob o prisma da subjugação das mulheres na sociedade (LOURO, 1995). Na educação a sina se repete, e em certos casos, até surge um apego ao desenvolvimento de metodologias alternativas que tenham por objetivo conscientizar o corpo estudantil para que se mitiguem as desigualdades entre homem e mulher. Isto justifica-se, sobretudo, devido às restrições que a estruturação das sociedades impõem ao exercício pleno das identidades de gênero, nem sempre entendidas de maneira plural.

Desta maneira, acaba-se por acreditar que desenvolvermos atividades que coloquem a mulher no centro dos debates de gênero mitigará tais desigualdades. Contudo, a determinação de papéis sociais está impregnada à "matriz heterossexual", a mesma que fomenta a heterossexualidade compulsória que torna a escola um espaço de reprodução de desigualdades sociais. Esta "matriz heterossexual" termo utilizado por Judith Butler (2008) em "Problemas de Gênero: feminismo e subversão de identidades", diz respeito a uma "grade de inteligibilidade cultural por meio da qual os corpos, gêneros e desejos são naturalizados" (BUTLER, 2008, p. 215-216).

Mesmo antes do nascimento, as famílias se preparam para receberem um novo parente. Este preparo também age enquanto reprodutor de uma ordem social desigual. Ao reforçarem o binarismo a que a heterossexualidade compulsória instiga, pelas vias do consumo de produtos de cor rosa, para meninas, azuis, para meninos, e amarelas, nos casos de não saberem o sexo (entendido comumente como representação de genitálias biológicas), as possibilidades de existência de determinado indivíduo se limitam ao ser homem e ao ser mulher, idealizando comportamentos que vão distinguir sexos, sem o entendimento do que é gênero.

Butler (2008) concebe identidade de gênero como uma construção performática, um efeito não-linear entre gênero, sexo e desejo de dada produção discursiva. Em sua complexidade, "a identidade de gênero pode ser re-concebida como uma história pessoal/cultural de significados recebidos, sujeitos a um conjunto de práticas imitativas que se 
referem lateralmente a outras imitações" (BUTLER, 2008, p. 197). "Nesse sentido, o sujeito não é anterior ao que ele expressa, mas é justamente um efeito do que ele expressa." (FIRMINO, PORCHAT, 2017, p. 57).

Desse modo, entendemos que o sexo é produzido pelo gênero, e este é "um conjunto de atos repetidos no interior de uma estrutura reguladora altamente rígida, a qual se cristaliza no tempo para produzir a aparência de uma substância, de uma classe natural de ser" (BUTLER, 2008, p. 59). A importância de se discutir questões de gênero na escola nos faz observar que

a. Os corpos que vão à escola são docilizados sob ação de um paradigma de gênero e sexualidade estruturante;

b) Os debates de gênero vão além da condição social da mulher.

Não obstante, o papel da educação geográfica é dialogar com tais observações, a fim de que se estenda à prática pedagógica com maior afinco uma proximidade entre as mais diversas realidades dos sujeitos, assegurando suas inteligibilidades performáticas próprias, resultadas de um processo esclarecido de autocompreensão. Silva (2010), leva-nos a crer na possibilidade de subversão de paradigmas a partir da própria geografia.

\begin{abstract}
A geografia incorpora a noção de construção social do sexo, gênero e desejo e as relações de poder inerentes a ela, num processo de permanente tensão e movimento. Ao incorporar a performatividade como o exercício do gênero, entendido como representação social, a geografia evidencia a importância da incorporação do espaço e do tempo nas análises das experiências da vivência cotidiana e concreta e as possibilidades de subversão da própria ordem compulsória de gênero da sociedade heteronormativa. (SILVA, 2010, p. 43).
\end{abstract}

Por intermédio da inserção das cotidianidades performáticas em sua prática, a educação geográfica, apesar de nem sempre sensível às geograficidades e territorialidades dos próprios estudantes, apresenta potencial questionador, e este é o primeiro passo a ser dado rumo à subversão. Toda dúvida advém de um questionamento, e todo questionamento é pertinente à desestruturação de um discurso que reforça desigualdade.

Não nos adiantaria propor um diálogo acerca do ensino de geografia desconsiderando os sujeitos que fazem parte do seu tecer, pois falar de educação geográfica é pensar na tríade dinâmica socioespacial, formação de professores e ensino de geografia. Como aponta Callai (2015, p. 134), "O ensino de Geografia, bem como dos demais componentes curriculares, tem que considerar necessariamente a análise e a crítica que se faz atualmente à instituição escola, situando-a no contexto político social e econômico do mundo e em especial do Brasil.”, é a 
partir da crítica que o professorado, também constituído por corpos docilizados, podem enxergar os elementos que outrora os docilizaram, para então se debruçarem sobre a (des)construção contínua de conhecimento com seus estudantes.

Apesar de pautada como temática transversal pelos documentos oficiais que, em um plano hipotético, regem a educação brasileira, - sendo estes as Diretrizes Curriculares Nacionais (DCNs), os Parâmetros Curriculares Nacionais (PCNs) e a Base Nacional Comum Curricular (BNCC), "gênero" se constitui, como categoria de análise funcional que subsidia(ria) a geografia escolar a fim do saber ouvir os gritos silenciosos dos grupos sociais minoritários.

“É indispensável que reconheçamos que a escola não apenas reproduz ou reflete as concepções de gênero e sexualidade que circulam na sociedade, mas que ela própria produz" (LOURO, 1997, p. 80-81). A tomada de consciência por parte dos envolvidos no processo de desconstrução é processual, demanda tempo como demanda espaços. Portanto,

É imprescindível que a escola compreenda e incorpore mais as novas linguagens e seus modos de funcionamento, desvendando possibilidades de comunicação (e também de manipulação), e que eduque para usos mais democráticos das tecnologias e para uma participação mais consciente na cultura digital. (BNCC, 2017, p.60).

Substancialmente, o ensino de geografia está impregnado do que é vívido. Incorporando brandamente questões sociais, "permite e encaminha o aluno a um aprendizado que faz parte da própria vida e como tal pode ser considerado em seu significado restrito e extrapolado para a condição social da humanidade" (CALLAI, 2015, p. 144). Sem embargo, não foge à crítica que Morin (2006) faz aos "saberes separados".

Para o autor, "os desenvolvimentos disciplinares das ciências não só trouxeram as vantagens da divisão do trabalho, mas também os inconvenientes da superespecialização, do confinamento e do despedaçamento do saber" (MORIN, 2006, p. 15). Desta maneira, o prosseguimento de práticas separatistas perfaz conhecimento, ao passo que ignorância e cegueira. Isto porque a hiperespecialização de que trata o autor, obscurece a relação entre o global e o essencial, sendo estes, respectivamente, desafios multidimensionais do ensinar. Ora, se o global se preocupa com a totalização dos fatos, fragmentados em parcelas, vide "os desenvolvimentos disciplinares das ciências", de que se ocupa o saber essencial?

Em "Os sete saberes necessários a educação do futuro" Morin (2000), evidencia as lacunas entre o educar na atualidade e o educar para o futuro. O autor correlaciona 1) "As cegueiras do conhecimento"; 2) "Os princípios do conhecimento pertinente"; 3 ) "Ensinar a 
condição humana"; 4) "Ensinar a identidade terrena"; 5) "Enfrentar as incertezas"; 6) "Ensinar a compreensão" e 7) "A ética do gênero humano".

O "erro" sempre fora historicamente repugnado pela eloquente fragilidade do cientificismo; o literato busca integra-lo no processo de construção do conhecimento, uma vez que a fragmentação das disciplinas escolares ao pluralizar seus campos de saberes, tracejam uma espécie de linha abissal (SOUSA SANTOS, 2007) entre os conhecimentos outrora dialogados. Este efeito abissal enaltece determinada área de conhecimento e acaba por anular diálogos entre saberes, reproduzindo o erro enquanto devolutiva. $\mathrm{O}$ enaltecer de uma parte se torna, necessariamente, a negação de outra, - nesta unilateralidade, Morin (2000) propõe que se pense as relações entre o todo e as partes.

Como um quebra-cabeças incompleto, a parte que falta na educação é a humanização. No sentido de cada vez mais educar para o conhecimento de si e do mundo, o autor defende que a condição humana deveria ser o centro de todo o ensino (MORIN, 2000).

\footnotetext{
O ser humano é a um só tempo físico, biológico, psíquico, cultural, social, histórico. Esta unidade complexa da natureza humana é totalmente desintegrada na educação por meio das disciplinas, tendo-se tornado impossível aprender o que significa ser humano. É preciso restaurá-la, de modo que cada um, onde quer que se encontre, tome conhecimento e consciência, ao mesmo tempo, de sua identidade complexa e de sua identidade comum a todos os outros humanos. (MORIN, 2000, p. 15)
}

Ao percebermos que a ciência afastara a tão necessária humanização ao ensino (particularmente falando) de geografia, enfatizamos, respaldados sob a óptica de Morin (2000), o princípio da incerteza enquanto fonte de (in)segurança, a fim de propor questionamentos aos ordenamentos sociodiscursivos que padronizam a sociedade. Alia-se a isto o ensinar a compreensão enquanto ponte solidificável para a comunicação. "Daí decorre a necessidade de estudar a incompreensão a partir de suas raízes, suas modalidades e seus efeitos. Este estudo é tanto mais necessário porque enfocaria não os sintomas, mas as causas do racismo, da xenofobia, do desprezo" (MORIN, 2000, p. 17).

Ao que tange seu sétimo saber, Morin se distancia de um imaginário coletivo fundamentalista-cristão, em que os bons costumes, externalizados aos montes, se baseiam em crenças individuais; ele acredita que "A ética não poderia ser ensinada por meio de lições de moral. Deve formar-se nas mentes com base na consciência de que o humano é, ao mesmo tempo, indivíduo, parte da sociedade, parte da espécie.” (MORIN, 2000, p. 17).

A realidade de uma escola perversa nos afasta do diálogo como interposto à subversão. Como, pois, pensar no ensino de geografia para a diversidade, se o saber-ouvir e o saber-falar, 
se fizeram abstratos à romantização da instituição escolar? A rede de relações que (des)qualificam-na enquanto um espaço plural pode ser re-concebida?

Deveria. Gramaticalmente, a conjugação no futuro do pretérito diz respeito ao que, no passado, poderia ter acontecido, mas não aconteceu. Um ensino que remonte à cidadania tem a potencialidade de reconstituir as defasagens do ensino. Mas é preciso "pés no chão". Diante do contexto sociopolítico claramente fascista a que o Brasil encena atualmente, as dificuldades se agravam; projetos de leis ameaçam a liberdade didática do professorado, incentivam os alunos a exporem seus professores que pensam diferente dos mentores de uma (velha e conhecida) ordem social que aos poucos está se (re)constituindo. E o silenciamento não é uma alternativa.

Os estudantes devem (in)formar-se "a respeito das forças ideológicas que influenciam e restringem suas vidas" (CALLAI, 2015, p. 149). Bem como "os temas estudados devem estar inseridos num quadro de referências e explicações que deem significado para eles, que demonstrem a importância de compreender estas realidades que podem ser locais, mas que expressam/demonstram questões que são da humanidade." (CALLAI, 2015, p. 146).

A geografia sempre se utilizou da interdisciplinaridade como via à renovação; aqui, não fujamos à regra. Vale salientar que não propõe-se aqui indicar e/ou construir metodologias para a inserção dos debates de gênero na educação geográfica a partir da literatura, por ora, cabe-nos apenas complementar a reflexão que nos dispusemos a fazer, agregando agora o predicado desta interdisciplinaridade ao ensino de geografia.

Sabendo do recorte de gênero realizado neste trabalho, concentremo-nos na literatura como aporte sensível às leituras de mundo, estas que "só tornam-se realmente aptas a pensaragir no mundo, quando o que lhe torna possível é a realidade cotidiana, a vida, os elementos circundantes que confeccionam as identidades e as identificações” (BOTÊLHO, 2018, p. 64). Morin esclarece que:

É a literatura que nos revela, como acusa o escritor Hadj Garm` Oren, que - todo indivíduo, mesmo o mais restrito à mais banal das vidas, constitui, em si mesmo, um cosmo. Traz em si suas multiplicidades internas, suas personalidades virtuais, uma infinidade de personagens quiméricos, uma poliexistência no real e no imaginário, o sono e a vigília, a obediência e a transgressão, o ostensivo e o secreto, pululâncias larvares em suas cavernas e grutas insondáveis. Cada um contém em si galáxias de sonhos e de fantasias, de ímpetos insatisfeitos de desejos e de amores, abismos de infelicidade, vastidões de fria indiferença, ardores de astro em chamas, ímpetos de ódio, débeis anomalias, relâmpagos de lucidez, tempestades furiosas. (MORIN, 2003, p. 44) 
Assim, a interdisciplinaridade não deve conceber a literatura como fonte secundária à ação. Em oposição à visão pragmática de que a literatura "serve à geografia", é que concebemo-la enquanto ciência, cultura, arte e vida. Nas suas entrelinhas, viabiliza análises interpretativas, sugerindo lentes ficcionais que não distorcem a realidade, ao contrário, ajudam a enxerga-la de maneira elucidativa.

Silva e Barbosa afirmam quem "o saber espacial somente tem sua plenitude na cognoscibilidade do sujeito ao compreender a relação étnico-espacial” (2014, P. 82). Toda organização espacial é reflexo das relações de gênero hierarquizadas, em que os homens são 'realçados' em relação às mulheres (SILVA, 2009). Compreender isto é analisar que, apesar da categoria gênero dispensar a dualidade entre homem e mulher, esta mesma significação serve à desconstrução. Sobremaneira, as conformidades do sujeito personagem translucida o desenvolvimento de seu modo de estar no mundo, configurando uma geograficidade a partir do contato tido para com determinado espaço.

À vista disso, retomando à Morin (2000), as correlações entre os 7 saberes pode se qualificar em questionamentos; elencando obras literárias que retratem espacialidades, enreda ao professor fomentar o diálogo acerca das performatividades nas narrativas literárias, sabendo que estas são assessoradas por quesitos analíticos como etnia, classe e, singularmente, o gênero, essencializado no binarismo a que recai toda estrutura social vigente.

\begin{abstract}
Utilizar o conceito de gênero, que implica uma postura relacional dos universos femininos e masculinos, não leva à necessidade de análises comparativas envolvendo homens e mulheres, embora haja tradição deste perfil de produção científica. A dimensão relacional que a ideia de gênero concebe é a compreensão de que os seres não estão isolados e estáticos e os recortes sociais estabelecidos no processo de pesquisa devem ser considerados de forma relacional e processual na estrutura socioespacial a que pertencem (SILVA, 2010, p. 40).
\end{abstract}

As artes, bem como a literatura e sua poética, driblam o tradicionalismo e remetem o indivíduo à epifania. E é deste "desencargo" que se encarrega o saber essencial, aproximando, questionando, subvertendo. Em tempos sem tempo, os pequenos passos conduzem o futuro com maestria.

\title{
4 PARA NÃO CONCLUIR...
}

Darcy Ribeiro dizia que a crise da Educação no Brasil não era uma crise, mas um projeto. O cenário político em que o país se encontra hoje reflete exatamente isso. É demasiado complexo concluir um trabalho que tem como temática o debate sobre questões de 
gênero no ensino, quando essas mesmas não são bem vindas à escola. Por isso propomos não concluir.

As lutas diárias da sociedade civil contra os negligenciamentos da diversidade performática ecoam sobre o sofrimento tido por corpos plurais para com as mais variadas violências: simbólica, psicológica, física, fatal. A escola poderia acolher, mas, cerceada pelo reprodutivismo, escolhe o silêncio. Nele, ecoam gritos silenciosos de um presente marcado pelo passado e de um futuro incerto. A geografia não se distancia, mas que seu ensino enquanto prática próxima, pode se fundamentar no diálogo.

Tão posto em xeque por "vulnerabilizar" a postura do professorado, também reflexo de um sistema de ensino escrupuloso, o diálogo age enquanto elo de sensibilização. Evidencia, pelas vias da interdisciplinaridade do ensino de geografia com a literatura, que enquanto sujeitos que agem sobre o mundo, somos indivíduos poliexistentes e estas múltiplas fáceis, em si e outrem, devem ser valorizadas. A importância de se discutir gênero na educação geográfica é uma forma de propor um ensino não-violento.

Após refletirmos sobre as influências sofridas pela geografia escolar diante os ordenamentos socioespaciais que a limitavam e que, decerto, a influenciam até hoje, é sabido sua potencialidade. Em uma relação, também, política de existência, a disciplinaridade (escolar) da ciência geográfica concebe a sistematização de saberes que incentivam um desvendar de possibilidades.

Dialogar com o imaginário cultural, pondo em xeque amarras e ideologias que limitam espacialidades, evidencia a contraposição a que Morin (2006) se atém. A cabeça bem cheia ou a cabeça bem feita? O que queremos à educação geográfica? O projeto de (des)governo se 'respalda' na censura, na docilização e no controle biopolítico dos corpos; a escola, agindo enquanto mecanismo para esta consolidação, só tem uma alternativa: ensinar para a vida.

\section{REFERÊNCIAS}

ALCÁNTARA COSTA, A.; TEIXEIRA, A.; MACEDO, V. Introdução. In: Ensino e gênero: Perspectivas transversais. 2011.

BOTÊLHO, L. A. V. Temáticas de diversidade na formação e prática dos professores de geografia: desafios e possibilidades. Revista de Ensino de Geografia, Uberlândia, v. 9, n. 17, p. 59-73, 2018.

BOURDIEU, P. O Poder Simbólico. Trad. Fernando Tomaz. Rio de Janeiro: Bertrand Brasil, 2001 . 
BOURDIEU, P.; PASSERON, J-C. A Reprodução: Elementos para uma Teoria do Sistema de Ensino. 2. ed. Petrópolis: Ed. Vozes 2009.

BRASIL. Ministério da Educação. Secretaria da Educação Básica. Base nacional comum curricular. Brasília, DF, 2016. Disponível em: <

http://basenacionalcomum.mec.gov.br/\#/site/inicio>. Acesso em: dez. 2016.

BUTLER, J. Problemas de gênero: feminismo e subversão da identidade. Tradução de Renato Aguiar. Rio de janeiro: Civilização Brasileira, 2008.

CALLAI, H. C. A Geografia e a escola: muda a geografia? Muda o ensino? Terra Livre, v. 1, n. 16, p. 133-152, 2015.

COLASANTI, M. et al. A moça tecelã. Doze reis e a moça no labirinto do vento, v. 11, 2000 .

COPATTI, C. O ensino da geografia na contemporaneidade e a prática docente para o despertar da criatividade. Revista Espaço e Geografia, v. 20, n. 1, 2017.

FIRMINO, F. H.; PORCHAT, P. Feminismo, identidade e gênero em Judith Butler: apontamentos a partir de "problemas de gênero". DOXA: Revista Brasileira de Psicologia e Educação, v. 19, n. 1, p. 51-61, 2017.

FOUCAULT, M. A ordem do discurso. São Paulo: Loyola, 1996.

LOURO, G. L. Gênero, história e educação: construção e desconstrução. Educação \& Realidade, v. 20, n. 2, 1995.

LOURO, G. L. Gênero, sexualidade e educação: uma perspectiva pósestruturalista. 2. ed. Rio de Janeiro: Vozes, 1997.

MISKOLCI, R. Um corpo estranho na sala de aula. Afirmando diferenças: montando o quebra-cabeça da diversidade na escola, v. 2, p. 13-26, 2005.

MOREIRA, R. A Geografia serve para desvendar máscaras sociais. Geografia, teoria e crítica: o saber posto em questão. Petrópolis: Vozes, p. 33-63, 1982.

SANTOS, B. S. Para além do pensamento abissal: das linhas globais a uma ecologia de saberes. Revista crítica de ciências sociais, n. 78, p. 3-46, 2007.

SANTOS, M. Metamorfoses do espaço habitado. São Paulo: Hucitec, v. 4, p. 136, 1988.

SANTOS, M. Técnica, espaço, tempo: globalização e meio técnico-científico informacional. São Paulo: HUCITEC, 1994, 190 p.

SILVA, J. M. Fazendo geografias: pluriversalidades sobre gênero e sexualidade. Geografias Subversivas: discursos sobre espaço, gênero e sexualidades. Ponta Grossa: Todapalavra, p. 25-54, 2009.

SILVA, J. M. Geografias feministas, sexualidades e corporalidades: desafios às práticas investigativas da ciência geográfica. Espaço e Cultura, n. 27, p. 39-56, 2010.

SWAIN, T. N. Entre a vida e a morte, o sexo. Revista Labrys Estudos Feministas, 2006. 